\title{
JUVENTUDES E PEDAGOGIAS CULTURAIS: EXPERIMENTAÇÕES DE SI E (RE)PRODUÇÃO DE FEMINILIDADES NAS PRÁTICAS DE TIRAR SELFIES
}

\author{
Evelyn Santos Pereira ${ }^{1}$ \\ Bianca Salazar Guizzo ${ }^{2}$ \\ Luiz Felipe Zago ${ }^{3}$
}

Resumo: O principal objetivo do artigo é analisar como são ensinadas e aprendidas determinadas formas de incorporar o gênero feminino através da produção e publicação de selfies entre meninas, a partir da perspectiva teórica dos Estudos Culturais e dos Estudos de Gênero pós-estruturalistas. Metodologicamente foram propostos grupos de debates com jovens meninas estudantes dos anos finais do ensino fundamental pertencentes a uma escola pública estadual do Rio Grande do Sul. Os resultados sublinham aspectos do gênero feminino que são valorizados culturalmente quando as meninas produzem seus corpos como imagem. Além disso, mostra-se que a publicação e a publicação das imagens de si geram efeitos nas formas como as feminilidades são significadas e vividas pelas meninas.

Palavras-chave: Juventudes; Feminilidades; Identidades; Imagem.

\section{YOUTHS AND CULTURAL PEDAGOGIES: EXPERIMENTATIONS OF ONESELF AND (RE)PRODUCTION OF FEMINILITIES IN THE PRACTICES OF TAKING SELFIES}

\begin{abstract}
The main goal of the article is to analyze the pedagogical ways by which the female gender is embodied by young girls through the production of and publication of selfies (selfportraits). The theoretical approach employed is based on the Cultural Studies and Gender Studies in the field Education. The methodology design consisted of three meetings for discussion with female students of one level of Public Brazilian High School. The results address aspects of the female gender that are culturally valued in the very moment when the girls make an image of their bodies. It is also shown that the production and publication of self-portraits imply certain effects in the ways how feminilities are signified and experienced by the girls.
\end{abstract}

Keywords: Youths; Feminilities; Identities; Image.

\footnotetext{
${ }^{1}$ Doutoranda em Educação, Mestre em Educação pela Universidade Luterana do Brasil. Licenciada em Pedagogia pela Universidade Estadual do Rio Grande do Sul.

2 Doutora e Mestre em Educação pela Universidade Federal do Rio Grande do Sul. Licenciada em Pedagogia pela mesma Universidade. Professor do Curso de Pedagogia e do PPGEDU da ULBRA

${ }^{3}$ Doutor e Mestre em Educação pela Universidade Federal do Rio Grande do Sul. Bacharel em Comunicação Social - Jornalismo pela mesma Universidade. Professor do Curso de Comunicação Social e do PPGEDU da ULBRA.
} 


\section{INTRODUÇÃO}

$\mathrm{Na}$ perspectiva dos Estudos Culturais, entende-se que estamos expostos/as a múltiplas Pedagogias Culturais através das quais somos ensinados/as, educados/as e interpelados/as (COSTA; SILVEIRA; SOMMER; 2003). O conceito de Pedagogias Culturais considera como pedagógicos os diferentes artefatos culturais que circulam na sociedade, em especial aqueles produzidos e consumidos no âmbito da mídia. Atualmente, diferentes mídias podem ser consideradas pedagógicas, uma vez que nos capturam, proliferam nossos entendimentos e imaginações e interferem em nossas maneiras de se comportar e de agir. Giroux e McLarem (1995, p. 144) argumentam que "existe Pedagogia em qualquer lugar em que o conhecimento é produzido, em qualquer lugar em que existe a possibilidade de traduzir experiências".

Nesse artigo, objetivamos discutir como são ensinadas e aprendidas determinadas formas de incorporar o gênero feminino por meio da produção e da publicação de selfies ou imagens de si, em que o/a autor/a da fotografia é, ao mesmo tempo, a figura central da imagem. Essas selfies são entendidas como pedagógicas, uma vez que reiteram e/ou escapam de representações sobre modos de ser jovem mulher na contemporaneidade. Analisar as representações que circulam na cultura nosajuda a compreender a forma como construímos nossas identidades, como nos posicionamos em relação aos outros e como significamos a cultura da qual fazemos parte.

Para problematizar os modos como jovens meninas são ensinadas sobre formas de incorporar o gênero feminino por meio da produção e da publicação de selfies, em termos metodológicos, foram propostos encontros de debates com nove estudantes, compreendidas na faixa etária de 15 a 17 anos, vinculadas aos anos finais do ensino fundamental de uma escola pública estadual de uma cidade litorânea do Rio Grande do $\mathrm{Sul}^{4}$. Os encontros foram gravados e as transcrições decorrentes deles compuseram o material empírico da pesquisa da qual se originou esse artigo.

Entendemos que a contemporaneidade possibilitou o desenvolvimento de uma infinidade de identidades, plurais, móveis, contraditórias, de resistência e, por vezes, avessas às normas sociais que, durante séculos, aprisionaram os sujeitos em categorias

\footnotetext{
${ }^{4} \mathrm{O}$ projeto de pesquisa do qual se originou esse artigo foi submetido à Plataforma Brasil, avaliado e aprovado pelo Comitê de Ética da Universidade Luterana do Brasil, com o número CAAE 44114414.1.0000.5349.
} 
muito rígidas de gênero e de sexualidade (LOURO, 2007; WEEKS, 2007). No entanto, os atributos que, ao longo da história, foram sendo designados como propriamente femininos - por exemplo: beleza, sedução e graciosidade - continuam tendo grande força para definição/manutenção das identidades femininas que possuem maior legitimidade e, portanto, são repetitivamente reproduzidos por meninas e mulheres neste tempo. As falas das garotas, participantes da pesquisa, demonstraram isso em alguns momentos dos encontros realizados. Apesar delas também trazerem narrativas sobre equidade de gênero e liberdade feminina, elas acabavam se contradizendo e retomando entendimentos que reforçavam as normas binárias, as quais estabelecem comportamentos diferentes para homens e mulheres. É sobre isso que buscamos discutir a seguir.

\section{"Eu não gosto de guria estilo gurizinho [...] Mas essa aí eu achei muito gata".}

Dinah Quesada Beck (2012), em sua tese de doutorado, investigou como a utilização de uniformes escolares infantis reflete o modo como as meninas investem em seus corpos, a partir de práticas de embelezamento e consumo tão difundidas na contemporaneidade. Neste estudo, a pesquisadora mostra de que forma, desde a infância, meninas aprendem a exercer sobre si um cuidado com corpo e a aparência, em busca de se adequarem aos padrões de moda e de beleza fortemente associados ao gênero feminino. E argumenta que, provavelmente, os ensinamentos que elas aplicam em seus atos de embelezamento, desde tão pequenas, sejam lições que elas aprendem em casa, mas, de modo fundamental, diariamente por meio de variadas instâncias sociais e culturais às quais elas estão inseridas e engajadas (BECK, 2012).

Nesse sentido, são muitas as pedagogias culturais que propagam noções de identidade. Em relação às meninas, aprendem muito precocemente lições de cuidado e embelezamento do corpo. Liliane Madruga Prestes (2014) analisou de que forma as questões de gênero e sexualidade na infância são enfocadas na atualidade a partir das mídias eletrônicas, em especial, a internet. Para isso, a pesquisadora analisou o conteúdo de sites de jogos eletrônicos destinados ao público infantil, observando como as questões de gênero e sexualidade estavam ali imbricadas. Por meio das análises que ela desenvolveu dos jogos eletrônicos voltados para o público infantil feminino, percebemos inúmeros ensinamentos que vão desde os cuidados com a boa forma do corpo até a maneira de viver 
os relacionamentos amorosos. No site analisado pela pesquisadora, a maior parte dos jogos femininos traz temas como: cirurgia plástica, maquiagem, cuidado e proteção de bebês ou animais, conquista, sedução, namoro, casamento e tarefas domésticas.

Tanto a pesquisa de Beck (2012), como a de Prestes (2014) nos mostram pedagogias de gênero operando na cultura, ensinando meninas, desde muito pequenas, a se preocuparem com seus corpos e a investirem neles práticas diversas de cuidado e embelezamento. E, de certo modo, esses ensinamentos repercutiram nas falas das jovens nos encontros de discussão.

Em um desses encontros com as meninas, foram espalhadas sobre uma mesa algumas selfies encontradas na internet a partir da pesquisa do termo Body Positive - um movimento de mulheres que utilizam as redes sociais para divulgarem suas selfies e compartilharem mensagens que buscam positivar diferentes tipos de corpos. Além de incentivar que as mulheres gostem de seus corpos e se mostrem do jeito que são, mesmo que não estejam dentro dos padrões corporais propagados e reforçados como "ideais". Dentre essas selfies havia fotos de jovens mulheres que tinham cabelos curtíssimos e cujas axilas não estavam depiladas, o que deflagrou interessantes discussões as quais reproduzimos abaixo:

Sophia : nossa, ela tá com o suvaco peludo.

Carolina: oh (espanto).

Isabela: eu achei ela bonita.

Elisa: ah, ela é conhecida né? Ela é famosa.

Carolina: por que ela não depila o suvaco?

Carolina: [...] eu já acho estranha.

Sophia: [...] Nossa!

Carolina: falta de higiene.

Pesquisadora ${ }^{6}$ : gurias, algumas dessas fotos é sensual e [...]

Sophia: eu acho que essa aqui, se não tivesse o suvaco peludo, ela seria sexy.

Pesquisadora: sexy?

\footnotetext{
${ }^{5}$ Os nomes das meninas são fictícios.

${ }^{6}$ Apenas uma das autoras conduziu os encontros com as meninas.
} 
Sophia: é. Porque não tá aparecendo nada, mas ela tá [...]

Elisa: é que isso é bem estranho porque cada um julga uma coisa diferente, né? Tipo, o que é bonito pra ti [...] ela deve achar bonito, sei lá quem... o ciclo de amigos dela, deve ser uma coisa normal. Só que pra nós não é, entendeu? Então a gente acha feio porque não é uma coisa normal, mas se todo mundo fosse assim ela ia ser diva.

Carolina: fora o suvaco dela, ela continua linda.

Risos.

Isabela: isso pra mim é uma questão higiênica.

Fernanda: não depilar o suvaco (risos).

(Encontro: 17/08/2015)

Carolina: o suvaco cabeludo eu achei muito estranho (risos). Tem uma cara de homem. [...] Parece um guri de batom e rímel.

Elisa: eu não gosto de guria estilo gurizinho, sabe? Mas essa aí eu achei muito gata.

Fernanda: apesar do suvaco cabeludo.

Carolina: como a MileyCyrus ${ }^{7}$, ela tem um estilo gurizinho.

Julia: agora, né? Antes ela era linda.

Carolina: e ela tá namorando uma mulher também.

Sophia: quem?

Carolina: a MileyCyrus. Uma modelo da... esqueci o nome.

Elisa: eu não achei ela muito bonita.

(Encontro: $17 / 08 / 2015)^{8}$

As possibilidades de autorrepresentação que a internet criou abrem muitas brechas para que formas alternativas de viver as identidades de gênero tenham visibilidade e potencialidade. Entretanto, assim como as imagens apresentadas às meninas borram e

\footnotetext{
${ }^{7}$ Miley Ray Cyrus é atriz, cantora, compositora e empresária norte-americana. Cyrus ficou mais conhecida em 2006 por interpretar Miley Stewart/Hannah Montana na série da Disney Channel, Hannah Montana. Atualmente, ela vem causando muitas polêmicas na mídia decorrentes de seu comportamento e aparência fora dos padrões.

${ }^{8}$ Os trechos transcritos dos grupos de discussão com as meninas serão apresentados em itálico, dentro de caixa de texto.
} 
bagunçam as fronteiras e normas de gênero, elas também funcionam para marcar o lugar da norma, mostrando o que o gênero feminino não pode ser. Guacira Lopes Louro (2013) argumenta que, enquanto as posições de gênero e de sexualidade multiplicam-se e tornamse mais visíveis, grupos e setores tradicionais da sociedade renovam seus ataques contra essas identidades consideradas "desviantes", buscando manter a ordem e os valores tradicionais. Nessas tensões e disputas, as identidades vão se afirmando. Algumas, de forma mais legitimada que outras, uma vez que este processo é sempre permeado por relações de poder.

De acordo com a perspectiva pós-estruturalista, gênero é um "processo", é um "fazer" que ganha sentido na repetição contínua de atos que são produzidos pelas leis e normas que buscam regulá-los (BUTLER, 2008). Desse modo, as marcas de gênero são produzidas como um efeito das normas e dos discursos regulatórios, exercidos por muitas instâncias sociais, sobretudo, entre os próprios sujeitos. Podemos observar essa regulação em torno da produção de corpos femininos através das falas anteriores. Os corpos das jovens mulheres constantes nas selfies apresentadas às meninas participantes da pesquisa não se enquadram no que, convencionalmente, se espera para o gênero feminino, porque as meninas das imagens não depilam certas partes do corpo que as mulheres "devem" depilar e cortam seus cabelos de uma maneira que é esperada para homens. A regulação em torno das definições das identidades de gênero, nesse sentido, é exercida pelas meninas participantes da pesquisa no momento em que elas dizem que as meninas apresentadas nas selfies têm estilo gurizinho, ou como disse Carolina: cara de homem, parece um guri de batom e rímel. Isso sugere que há marcas corporais que deslizam e "vazam" entre os corpos, como o corte de cabelo e determinadas zonas corporais com pelos ou sem pelos (axilas, pernas, buço), e que fazem com que uma menina seja posicionada como "gurizinho".

Louro (2013) chama a atenção para a multiplicação de sujeitos que constituem suas identidades escolhendo a ambiguidade, a fronteira, o contrassenso como lugar social. Denominados como queer, tais sujeitos não querem ser enquadrados e aceitos em categorias fixas de gênero e sexualidade. Segundo a pesquisadora:

Queer é tudo isso: é estranho, raro, esquisito. Queer é, também, o sujeito da sexualidade desviante - homossexuais, bissexuais, transexuais, travestis, drags. É o excêntrico que não deseja ser "integrado" e muito menos "tolerado". Queer é um jeito de pensar e de ser que não aspira o centro nem o quer como referência; um jeito de pensar que desafia as 
normas regulatórias da sociedade, que assume o desconforto da ambiguidade, do "entre lugares", do indecidível. Queer é um corpo estranho, que incomoda, perturba, provoca e fascina (LOURO, 2013, p. $8)$.

Esses "corpos estranhos" povoam a internet com selfies que, muitas vezes, buscam justamente causar a estranheza que as meninas da pesquisa expressaram ao verem as referidas selfies. Mas, assim como sua definição é ambígua, igualmente o são seus efeitos, pois, enquanto corroboram certas definições e representações tradicionais de gênero e sexualidade, multiplicando as referências identitárias contemporâneas, também reforçam as normas que buscam desafiar, porque mostram aquilo que o gênero feminino precisa se afastar para ser definido e afirmado.

Como podemos observar no trecho apresentado anteriormente, basta um aspecto não se "enquadrar" no que é permitido ao feminino para que este corpo seja estranhado e rechaçado. No exemplo trazido de MileyCyrus, Julia disse que, antes de ter "estilo gurizinho", ela era linda. Sendo assim, as noções de beleza e de feminilidade são definidas a partir das marcações do que um corpo feminino e lindo não é. Elisa, por sua vez, traz uma fala que propõe uma compreensão de que o corpo, mais especificamente, as noções de beleza e as normas de gênero são construídas na cultura: a gente acha feio porque não é uma coisa normal, mas se todo mundo fosse assim ela ia ser diva. Contudo, os comentários sobre as axilas peludas mostram como tais normas nos envolvem e engendram. Apesar de Elisa perceber que o fato de depilar ou não as axilas é determinado pela cultura em que se vive, ela concorda com as colegas que o corpo feminino peludo é feio e demonstra falta de higiene.

Silvana Goellner (2008, p. 34) indica que a ciência do século XIX legitima uma educação do corpo visando torná-lo útil e produtivo. Para tanto, uma série de poderes e conhecimentosé investida sobre ele através de diferentes métodos disciplinares, os quais “compunham um conjunto de saberes e práticas voltadas para educação da gestualidade, a correção do corpo, sua limpeza e higienização" (GOELLNER, 2008, p. 35). Em meio a essa nova forma de conceber e cuidar o corpo, emergem com grande importância os discursos da saúde e da higiene:

A própria palavra "higiene", neste contexto, adquire outro significado. Deixa de designar "o que é são" e, portanto, de qualificar a saúde e passa a construir um conjunto de dispositivos e de saberes que atuam no corpo (GOELLNER, 2008, p. 35). 
A partir dos conhecimentos desenvolvidos nesse campo e das prescrições que visavam educar os sujeitos para exercerem sobre si cuidados para a manutenção de um corpo limpo, saudável e eficaz, certas práticas corporais foram sendo adotadas e naturalizadas ao longo da história. Desse modo, fomos sendo ensinados como nos mantermos limpos e saudáveis através de diversas práticas e rituais cotidianos. A partir dessas pedagogias voltadas aos cuidados com o corpo, homens e mulheres são educados de maneiras distintas. Para as mulheres, os discursos médicos ocupam-se em produzir saberes sobre a saúde reprodutiva e os cuidados específicos para a higienização de determinadas partes do corpo. Porém, a política de distribuição dos pelos nos corpos não teve sua origem na área da saúde e da higienização, apesar de, hoje em dia, não depilar-se ser sinônimo de falta de higiene, desleixo, relaxamento, especialmente quando se trata de mulheres.

O costume de as mulheres depilarem certas partes do corpo, como axilas, pernas e virilhas, foi disseminado por meio das tendências criadas no universo da moda. Desta forma, enquanto o costume de remover os pelos se torna uma condição para a definição de um corpo feminino, a presença deles nos corpos masculinos afirma uma identidade viril e máscula ao homem. Gradativamente, em especial, a partir do século XX foram sendo incorporados aos discursos da saúde aspectos do mercado do embelezamento. Na atualidade, é possível sugerir que os discursos da saúde e da beleza são produzidos em um movimento sincrético, o qual fundamenta e mantém o atual mercado global das aparências.

Todavia, podemos notar que o corpo como imagem, ou seja, o corpo em pose possibilita uma série de composições que pode representá-lo de forma mais feminina ou menos feminina. As meninas destacaram que em uma das selfies a elas apresentadas a figura central da imagem soube parecer mais mulher do que outra, em uma fotografia diferente. Podemos supor que tal afirmação decorre da incorporação feita de certos aspectos que marcam o gênero feminino, como: os acessórios que ela está utilizando, a maquiagem marcando bem a boca e os olhos e, principalmente, a expressão facial que parece querer seduzir. Desta forma, verificamos que o gênero é construído a partir de uma série de marcações que caracterizam o que é uma mulher e, portanto, o que não é - ou não parece ser - uma.

Em outro encontro, solicitamos que as meninas trouxessem em seus smartphones uma selfie delas da qual gostassem e uma que não gostassem. A partir disso, discutimos alguns aspectos do processo de produção daquelas imagens. 
Pesquisadora: e quantas selfies vocês fizeram, mais ou menos, até chegarem a essa?

(Grande agitação e burburinhos).

Eduarda: eu posso contar (olha no celular). Eu fiz cinco.

Antonela: ah, eu fiz muitas. Acho que umas dez.

Carolina: eu devo ter feito umas quinze. Pelo menos, umas quinze. Olha (mostra o celular).

Antonela: umas quinze. É, eu também.

Elisa: nossa, gente.

Sophia: nossa, eu só fiz essa.

Pesquisadora: a tua, Sophia?

Sophia: é que era no Snap ${ }^{9}$, então eu não tirei várias vezes, foi só uma.

Carolina: mas até no Snap eu tiro várias. Eu tiro, dai eu apago...

Elisa: ah, eu não. A minha eu devo ter tirado umas cinco vezes. Umas quatro ou cinco vezes.

Eduarda: eu também.

Antonela: eu tirei umas quinze.

Pesquisadora: umas quatro ou cinco, Elisa? Todo mundo é assim? Alguém faz diferente?

Carolina: Acho que ninguém consegue. É muito difícil tirar uma foto, uma vez e deu.

Julia: a Sophia conseguiu.

Isabela: mas essa aqui até que foi a segunda.

Sophia: não, mas é porque é no Snap, foda-se. Mas depois eu gostei.

Pesquisadora: então é difícil né, gurias? Bate, olha, não gosta, apaga.

\footnotetext{
${ }^{9} \mathrm{O}$ Snapchat é um aplicativo de troca de mensagens, fotos e vídeos instantâneos gravados através do próprio aparelho. O que caracteriza e diferencia o aplicativo de outros, como o WhatsApp, é a obrigação de determinar um tempo, de 1 a 10 segundos, para o conteúdo ser exibido. Depois deste tempo, o conteúdo some.
} 
Elisa: ainda mais que tu sabe onde tá teus defeitos. Então, tipo, primeira coisa que tu olha na foto é aquilo que tu não gosta. Daí tu sabe que tá aparecendo. Aí tu vai tirar outra pra não aparecer aquilo, ai aparece de novo. Ai tu fica nessas até não aparecer.

(Encontro 17/08/2015).

A selfie, como um recurso muito produtivo na composição de narrativas autobiográficas, na maioria das vezes, é produzida com o objetivo de mostrar o melhor de nós (aos olhares alheios e ao nosso próprio olhar) e esconder nossos defeitos. E como podemos perceber através das falas anteriores, não é fácil ficar bem nas fotos. Sendo assim, é preciso aprender a produzir-se em imagem ${ }^{10}$. É preciso fazer muitas selfies até que se chegue a um bom resultado, até que se consiga esconder ou minimizar os defeitos e divulgar nossa melhor versão. É nessa direção que Paula Sibilia (2016) argumenta que as construções de si estão cada vez mais voltadas para o olhar alheio e exteriorizadas, é possível afirmar que as selfies são estratégias importantes para a produção de identidades virtuais, pois, a partir das selfies produzidas e publicadas na internet, pode-se "criar" identidades. Contudo, entendemos que os efeitos da produção e publicação de selfies ultrapassam o ambiente virtual, uma vez que nos constituímos na relação com essas produções autobiográficas que veiculamos na rede. Nossas identidades estão sendo construídas em relação com as versões que produzimos de nós mesmos através de narrativas virtuais.

$\mathrm{Na}$ produção da selfie, o espelho é substituído por um aparelho de captura da imagem, e este aparelho possibilita outras experiências com o corpo, pois permite que nossas qualidades, assim como nossos defeitos sejam vistos e analisados sob diversos ângulos. Elisa disse que o primeiro aspecto que olha na imagem são os defeitos, então é preciso fazer várias fotos até que consiga fazer com que aquilo não apareça mais. Às vezes, é preciso fazer umas quinze, até que gostem da selfie produzida, pois como disse Carolina: Acho que ninguém consegue. É muito difícil tirar uma foto, uma vez e deu.

A partir das imagens que produzem de si próprias, as meninas vão experimentandose no gênero feminino, descobrindo seus corpos, ensaiando seus melhores ângulos e aprendendo a investir nos jogos de sedução. Através da produção e publicação de selfies, ao mesmo tempo em que as meninas aprendem formas de ser feminina em diversas

\footnotetext{
${ }^{10}$ Ao processo de aprender e ensinar a produzir-se em imagens chamamos de pedagoselfies, cujo sentido exploramos em outros trabalhos.
} 
instâncias da cultura e a partir de variados artefatos que nela circulam, elas testam essas aprendizagens e, assim, também ensinam. Pois as selfies não deixam de ser mais um meio para produção de representações de identidades femininas e, como tais, produzem significados sobre o que é "ser mulher".

Vale mencionar, a esta altura, as análises de Ruth Sabat (2008) acerca de alguns aspectos da publicidade (tomada como um artefato cultural que produz uma pedagogia). A autora argumenta sobre como a publicidade opera na cultura produzindo significados diversos em torno das identidades, a partir das imagens e dos textos que veicula àquilo que quer vender. Sabat (2008, p. 149) sustenta que a publicidade "comporta uma pedagogia destinada a ensinar procedimentos, a regular condutas, a direcionar desejos e comportamentos". Ela destaca que as imagens produzidas nos anúncios publicitários têm uma função de grande importância não só para a promoção da marca ou do produto, mas também reforçam a legitimação de determinadas convenções identitárias.

A publicidade impressa trabalha basicamente com imagens. As imagens produzem uma pedagogia, uma forma de ensinar as coisas do mundo, produzem conceitos ou pré-conceitos sobre diversos aspectos sociais, produzem formas de pensar e agir, de estar no mundo e de se relacionar com ele. A construção de imagens que valorizam determinado tipo de comportamento, de estilo de vida ou de pessoa, é uma forma de regulação social que reproduz padrões mais comumente aceitos em uma sociedade [...] A publicidade não inventa coisas, seu discurso, suas representações, estão sempre relacionadas com o conhecimento que circula na sociedade; suas imagens trazem sempre signos, significantes e significados que nos são familiares (SABAT, op. cit. p. 150).

Desse modo, a publicidade, por meio das imagens e textos que produz, não só busca seduzir o consumidor e despertar desejo pelo seu produto, como também, ao associálo a determinado modo ou estilo de vida, ensina formas de ser e estar no mundo, produzindo identidades sexuais, de gênero, de raça/etnia, de geração, de classe, etc.

De certa forma, as selfies que abarrotam as redes sociais todos os dias não deixam de ser anúncios publicitários de vidas pessoais, pois, como disse Denise Sant'Anna (2002, p. 106), na ordem tecnocientífica-empresarial, "aprofunda-se uma tendência [...] que é a de transformar todas as partes do corpo em imagem de marca e num marketing privilegiado do eu".

E, assim como ocorre nos anúncios publicitários, no marketing pessoal as imagens - selfies - geralmente vêm acompanhadas de textos - legendas -, que complementam ou 
direcionam a mensagem da imagem. Sabat (2008) ressalta que o texto serve para fixar e controlar os significados que a imagem pode produzir. De acordo com ela, "em um anúncio publicitário, imagem e texto constituem-se em uma unidade narrativa que tem como objetivo proporcionar ao/à consumidor/a uma leitura correta a respeito daquele produto que está sendo anunciado" (SABAT, 2008, p. 151).

Assim, podemos entender que as selfies que compõem as narrativas autobiográficas publicadas nas redes sociais operam da mesma forma que os anúncios publicitários, uma vez que, ao associarem imagem e texto, buscam positivar nossas identidades, nossas marcas pessoais e nossas experiências, atraindo e seduzindo o olhar do outro para o que temos de melhor. Tal como na publicidade, usamos imagens e textos para propagarmos nossas próprias vidas em uma sucessão de anúncios espetacularizados de nós mesmos. Nessa produção publicitária do eu, é preciso desenvolver habilidades para compor o cenário, escolher o figurino, a pose, a expressão, o ângulo, filtrar, editar, recortar. E, depois de ter produzido várias amostras, selecionar a melhor delas, escolher as palavras certas para legendar e em qual rede social aquela imagem terá um efeito mais adequado. Esse é o potente aspecto pedagógico da prática de produção e publicação das selfies entre as meninas: saber produzir e dar visibilidade às imagens de si, na busca de propagar belas versões do eu.

Portanto, entendemos que tanto as representações de feminilidade que são veiculadas pela mídia e pela publicidade, como aquelas que são divulgadas por meninas e mulheres nas redes sociais produzem pedagogias de gênero. Trazemos a seguir um trecho das discussões no qual as garotas selecionaram quais tipos de selfies elas postariam em suas redes sociais e quais não postariam, mostrando quais aspectos do corpo julgam relevantes de serem exibidos e quais não só não são relevantes, como também podem causar "má impressão".

Pesquisadora: agora cada uma pega uma foto que postaria e uma que não postaria.

Pesquisadora: Eduarda, pode começar mostrando qual foto tu postaria?

Eduarda: por que eu? Eu postaria essa porque não aparece nada. Parece uma blusa. E não postaria essa.

Pesquisadora: Não postaria? Por quê?

Eduarda: não. Porque ela está de calcinha e sutiã e daí, sei lá, vai ficar mal falada.

Pesquisadora: mesmo se tu tivesses esse corpo?

Momento: diálogos em educação, E-ISSN 2316-3100, v. 26, n. 2, p. 25-43, jan./jun. 2017 
Eduarda: mesmo se eu tivesse esse corpo. Não postaria.

Pesquisadora: mas na outra foto ela tá de sutiã.

Eduarda: mas não aparece, né. Parece uma blusa. Só aparece os peitos grandes.

Pesquisadora: tá, Antonela?

Antonela: eu postaria essa. Eu posto essas fotos.

Isabela: normal.

Antonela: normal, eu posto essa aqui. E essa aqui eu não postaria porque, sei lá, acho que... tá de sutiã e tá aparecendo muito os peitos. Essa aqui já não tá tanto, olha, essa aqui já tá demais.

Pesquisadora: Isabela?

Isabela: essa aqui porque, primeiro, quando eu crescer quero ser igual ela.

(Risos).

Isabela: e segundo, porque tá normal, todo mundo tem foto assim. Normal.

Pesquisadora: ela tá sensualizando ou não?

Eduarda: tá

Isabela: ela tá sendo bonita pra foto.

Eduarda: é

Isabela: é, normal.

Isabela: e essa aqui, por que a pessoa vai postar uma foto assim?

Pesquisadora: por que ela tá sem a parte de cima da roupa?

Isabela: e porque isso aqui é uma calcinha também, né!

(Risos).

Pesquisadora: e tu, Julia?

Julia: eu não postaria essa aqui porque é uma coisa meio pessoal. E essa aqui eu postaria. Eu não achei nessa foto nada de mais.

Fernanda: é, eu também não.

Julia: apesar dela tá de sutiã, mas... nada a ver.

Fernanda: ela tá de sutiã? Parece uma blusa.

Fernanda: quem nunca postou uma foto que cortou o sutiã?

Momento: diálogos em educação, E-ISSN 2316-3100, v. 26, n. 2, p. 25-43, jan./jun. 2017 
Pesquisadora: tua vez, Ana.

Ana: eu não postaria essa porque ela tá de camisola no banheiro, sei lá, tá estranho. Tá vulgar isso aqui. E essa aqui eu postaria porque tá normal, ela tá de roupa e tá na academia.

Pesquisadora: todo mundo concorda com essa aqui? Alguém postaria?

Fernanda: eu postaria, porque eu achei nada a ver.

Pesquisadora: por quê?

Fernanda: porque tá sexy, só isso.

Antonela: parece um vestido.

Fernanda: é, parece um vestido.

Ana: não parece, aparece a calcinha dela.

Fernanda: mas eu postaria igual.

Antonela: ou uma saída de banho.

(Encontro 03/12/2014). ${ }^{11}$

A partir do que aqui está sendo compreendido como o processo de produção e publicação de selfies, entendemos que as garotas aprendem determinadas formas de ser feminina, aprendem como o corpo deve ser exibido e quais partes mostrar, quais atitudes são esperadas de seu gênero e como devem investir em suas aparências, estimuladas, em grande parte, pelo uso dos smartphones e pela sua participação em redes sociais.

Com a atividade proposta, de escolher uma selfie que elas postariam em suas redes sociais e outra que elas não postariam, foi possível observar que as imagens que representavam corpos femininos em poses sinuosas, com pouca roupa (preenchendo os requisitos daquilo que chamaríamos de "sensualidade") foram bastante valorizadas. Nas selfies escolhidas para serem postadas, as protagonistas expressam olhares penetrantes e bocas provocantes, curvam os corpos, empinam as bundas, jogam os cabelos para um lado ou para o outro, escolhem o ângulo que melhor enquadre o que pretendem dar destaque bunda, seios, cintura, pernas, expressões faciais ou o corpo todo. E pouco importa se esses corpos estão de sutiã - caso não esteja aparecendo muito - ou de camisola, nem que o

\footnotetext{
${ }^{11}$ Mesmo que nas falas das meninas haja menções a determinadas imagens, escolhemos não reproduzi-las aqui por se tratarem de fotografias nas quais aparecem os rostos das mulheres que, por terem sido tiradas da internet, não tiveram a possibilidade de consentir com o uso de sua imagem para uma pesquisa. Além disso, por não assumirmos a realização de análises visuais, damos privilégio aos argumentos discursivos que aparecem nas falas das meninas sobre quais selfies elas postariam ou não.
} 
objetivo de exibir o corpo e causar desejo esteja claro na imagem. O que importa, conforme disse Isabela, é estar sendo bonita pra foto.

Os critérios utilizados para separar as selfies entre aquelas que elas postariam e as que não postariam, assim como ocorreu para categorizá-las em grupos - nomeados pelas meninas como "selfie normal", "selfie mais ou menos" (ou sexy) e "selfie vulgar" -, se borraram e se confundiram em diversos momentos. As meninas pareceram estar em constante negociação entre os imperativos de gênero, os quais estimulam posturas e comportamentos de embelezamento, exibição e erotização dos corpos femininos, e as normas que os regulam.

É preciso ser muito perspicaz e habilidosa para saber atrair olhares, causar admiração e desejo, porém, sem parecer vulgar e não ficar mal falada. De acordo com os critérios das meninas, se aparecer demais o sutiã ou destacar muito os seios, se a camisola for transparente e aparecer a calcinha, se estiver somente de calcinha e sutiã ou, então, seminua em cima da cama, corre-se o risco de escorregar e ultrapassar o limite - cambiante e inexato - do publicável.

Lembremos que a publicização do eu feito em imagem, como no caso das selfies, busca o reconhecimento no olhar alheio para afirmação da identidade. A produção das subjetividades alterdirigidas (SIBILIA, 2016) precisa das aprovações do outro para sua definição. Desta maneira, a produção do corpo como imagem e, portanto, as escolhas sobre o que mostrar dele, como mostrar e para quem mostrar são exercitadas levando-se em consideração a forma como esta imagem será interpretada e julgada pelo outro. O medo de ficar mal falada ou de parecer vulgar faz com que as meninas produzam suas selfies, tendo como limite os discursos moralizantes em torno da vigilância do corpo e da sexualidade feminina. É importante destacar que cada vez que elogiavam determinada selfie ou mesmo nas imagens que escolheram para publicar na atividade anterior, elas enfatizavam que aquela foto era normal ou nada de mais, conforme disseram Isabela e Julia, respectivamente. Ou seja, aquele jeito de fazer-se em imagem estava dentro dos limites que vão sendo disputados para definir o que pode e o que não pode ser exibido de um corpo feminino.

\section{Considerações finais}

Hoje, as tecnologias eletrônicas, a internet e a própria noção de empoderamento trouxeram às mulheres muitas possibilidades de autorrepresentação. Não se pode negar que 
os diferentes movimentos sociais, entre eles, aqueles que reivindicam os direitos das mulheres e a equidade de gênero vêm abrindo brechas cada vez mais alargadas para que elas falem por si mesmas, para que tenham a possibilidade de mostrarem-se a partir de seus termos e que decidam qual parte e quais porções de seus corpos querem exibir.

Arthur Coelho Bezerra (2013) diz que a potencialização do livre acesso à produção, distribuição e consumo de informação e cultura proporcionada pela era digital na qual vivemos vem suscitando três dilemas importantes: o dilema da descentralização do acesso, o dilema da produção cultural amadora e o dilema da propriedade de bens culturais (BEZERRA, 2013, p. 250). Chamamos a atenção para os dois primeiros, pois entendemos que servem para pensarmos as mudanças ocorridas ao longo dos últimos anos no campo da cultura, em especial, no que tange à produção e à circulação de conteúdos diversos, como narrativas pessoais mantidas nas redes sociais, blogs, fanpages e sites que propagam ideias, conceitos, estilos de vida, arte, cultura e informação a partir do protagonismo de cada indivíduo "comum".

Sobre a descentralização do acesso a bens culturais, Bezerra (2013) ainda destaca que, apesar do otimismo de alguns estudiosos, como Pierre Lévy (1999), que acreditam que as novas tecnologias comunicativas teriam um impacto positivo sobre o exercício da democracia cultural e do exercício da cidadania, o uso que fazemos desses meios continua servindo ao modelo de sociedade ocidental capitalista. $\mathrm{O}$ autor argumenta:

É a cultura, locus dos valores sociais e visões de mundo, que determina, em última instância, os usos que serão feitos da tecnologia. Logo, a especulação sobre esses usos deve ser precedida de uma observação acerca do tipo de cultura que se manifesta na sociedade em questão (BEZERRA, 2013, p. 253).

A crítica que Bezerra (2013) desenvolve em torno da descentralização do acesso é voltada para o uso que fazemos dos meios de comunicação e informação no interior da cultura capitalista que vivemos. A internet, potencialmente um espaço que permite o protagonismo e a disseminação de informações e cultura de forma irrestrita e democrática, acaba por refletir e incentivar as características do mercado global de consumo, fortalecendo valores como a competição, o individualismo e o consumo compulsivo. A popularização das tecnologias eletrônicas propiciou e fez expandir a produção cultural amadora, chamando cada indivíduo a ocupar seu lugar no grande laboratório virtual chamado internet. E é nesse contexto que as selfies ganham potencialidade. Com a popularização da produção cultural, qualquer sujeito, seja um profissional/especialista ou 
não, tem ao alcance a possibilidade de produzir, distribuir e consumir informação e cultura no ambiente on-line.

Por sua vez, Paula Sibilia (2016), fazendo alusão à explosão de narrativas pessoais que decorrem do uso massivo das tecnologias eletrônicas e da internet, mostra como o mercado se apropria dos conteúdos produzidos por amadores para propagar marcas e produtos. De acordo com a pesquisadora, na web 2.0, somos interpelados a falar incansavelmente de nós mesmos, como nos diários íntimos dos séculos precedentes, e a interagir nesse ambiente produzindo cultura, informação e consumindo, expressando, além disso, gostos e preferências que serão captadas pelo mercado e se tornarão novos produtos a serem vendidos. Na era digital e do mercado global de consumo, a vida ordinária de cada sujeito pode - e deve - ser produzida e exibida em uma sucessão de espetáculos cotidianos.

Os trabalhos de Bezerra (2013) e de Sibilia (2016), cada qual a seu modo, destacam um ponto crucial que marca as construções identitárias nos dias de hoje: a facilidade que as tecnologias e os meios de comunicação e informação proporcionaram aos sujeitos para se autorrepresentarem. Para falarem de si e por si. Tanto a "produção cultural amadora" trazida por Bezerra, como "o show do eu", de Sibilia, nos mostram que, no atual cenário tecnológico em que vivemos, nossas identidades vão sendo produzidas na relação entre o que vemos, ouvimos e sentimos do outro e o que narramos e exibimos de nós mesmos.

A proliferação das tecnologias digitais e da internet permitiu que cada sujeito de posse de um computador, de uma câmera fotográfica ou um smartphone e com acesso à rede de internet possa utilizar os recursos dessas ferramentas para produzir narrativas e imagens de si mesmo e divulgá-las de acordo com seus próprios termos. Tal prática, possibilitada pelo contexto tecnocientífico que pauta a dinâmica cultural do século XXI, descentraliza o poder de representar que, dentro de limites culturais, regionais e econômicos, é democratizado àqueles que têm acesso ao aparato tecnológico e, assim, têm a chance de falarem e representarem a si.

$\mathrm{Na}$ atualidade, as mulheres estão disparando o botão da câmera, escolhendo as poses, os figurinos, editando as imagens e escrevendo as legendas de suas próprias fotografias. Elas tomaram a cena pública e dividem com os homens lugares de poder. Elas estão fazendo cinema, televisão, teatro, música, moda, revista, criando opinião pública, dirigindo grandes empresas e no comando de nações. Contudo, a possibilidade de narrar-se e de autorrepresentar-se não livra os sujeitos das amarras sedutoras e sutis - mas não menos eficazes e apertadas - dos tradicionais discursos e normas de gênero e sexualidade 
que permanecem enraizados na nossa cultura e são muito recorrentes nas representações femininas produzidas pela grande mídia e pelo mercado.

A juventude tem um papel de grande destaque para a ressignificação de valores conservadores e para o questionamento das normas que cercam o corpo e as normas de gênero e de sexualidade. Porém, muito do que as meninas participantes da nossa pesquisa nos indicaram é que elas também exercem sobre si e sobre as demais uma fiscalização das mesmas normas que, por vezes, querem subverter. Talvez seja esse caráter contraditório e ambíguo o que melhor define a juventude contemporânea. São meninas que estão aprendendo a ser mulheres e que não veem problemas em expressarem opiniões contraditórias, em gritarem liberdade e equidade de gênero, em tomarem a iniciativa nos relacionamentos amorosos, em exibirem seus corpos despudoramente, enquanto mantêm ideais de amor romântico, sonham com casamentos e filhos e não se importam em adequarem seus comportamentos às aprovações masculinas.

\section{REFERÊNCIAS}

BECK, Dinah. Com que roupa eu vou? Embelezamento e consumo na composição dos uniformes escolares. Tese de Doutorado. Programa de Pós-graduação em Educação, Faculdade de Educação, Universidade Federal do Rio Grande do Sul, Porto Alegre, 2012.

BEZERRA, Arthur Coelho Bezerra. Descentralização do acesso, produção amadora e propriedade intelectual: dilemas da cultura na era digital. Contemporânea: Revista de Comunicação e Cultura, v.11, n. 2, mai/ago 2013, p. 250-266.

BUTLER, Judith. Gender Trouble: feminism and the subversion of identity. New York: Routledge, 2008.

COSTA, Marisa Vorraber; SILVEIRA, Rosa Hessel; SOMMER, Luis Henrique. Estudos culturais, educação e pedagogia. Revista Brasileira de Educação, Rio de Janeiro, n. 23, p. 36-61. maio/ago, 2003.

GIROUX, H. McLAREN, P. Por uma pedagogia crítica da representação. In: SILVA, T. T.; MOREIRA, A F. (org.). Territórios contestados: o currículo e os novos mapas políticos e culturais. Petrópolis: Vozes, 1995, p. 144-158.

GOELLNER, Silvana V. A produção cultural do corpo. In: LOURO, Guacira Lopes; NECKEL, Jane Felipe; GOELLNER, Silvana Vilodre (Orgs.). Corpo, gênero e sexualidade: um debate contemporâneo na educação. Petrópolis: Vozes, 2008, p. 28-40.

LÉVY, Pierre. Cibercultura. São Paulo: Ed. 34, 1999. 
LOURO, Guacira Lopes. Pedagogias da sexualidade. In: LOURO, G.L. (Org.). O corpo educado: pedagogias da sexualidade. Belo Horizonte: Autêntica, 2007, p. 7-34.

LOURO, Guacira Lopes. Um corpo estranho: ensaios sobre sexualidade e teoria queer. Belo Horizonte: Autêntica, $2^{\circ}$ ed. 2013.

PRESTES, Liliane Madruga. Enredadas na rede: jogos para crianças (re)produzindo relações desiguais de gênero. Tese de Doutorado. Programa de Pós-Graduação em Educação, Faculdade de Educação, Universidade Federal do Rio Grande do Sul, Porto Alegre, 2014.

SABAT, Ruth. Gênero e Sexualidade para Consumo. In: LOURO, Guacira Lopes; NECKEL, Jane Felipe; GOELLNER, Silvana Vilodre (Orgs.). Corpo, gênero e sexualidade: um debate contemporâneo na educação. Petrópolis: Vozes, 2008, p. 149-159.

SIBILIA, Paula. O show do eu: a intimidade como espetáculo. Rio de Janeiro: Contraponto, 2016.

WEEKS, Jeffrey. O corpo e a sexualidade. In: LOURO, G.L. (Org.). O corpo educado: pedagogias da sexualidade. Belo Horizonte: Autêntica, 2007, p. 35-82. 